\title{
Optimalisasi Kualitas dan Kuantitas Produksi Keripik dengan Menggunakan Alat Pemotong Semi-Otomatis di Desa Pacalan
}

\author{
Riza Arif Pratama ${ }^{1 *}$, Indra Permana ${ }^{2}$ Muhammad Ikhsan ${ }^{3}$,Sahid Bayu Setiajit ${ }^{4}$ \\ ${ }^{1234}$ Universitas Tunas Pembangunan Surakarta \\ Email : rizaarifp@lecture.utp.ac.id
}

\begin{abstract}
Abstrak
Kelompok PKK merupakan kegiatan yang memberdayakan ibu - ibu dalam berpartisipasi untuk menunjang kemajuan desa. Permasalahan yang didapatkan dari kelompok PKK desa Pacalan karena hanya memakai peralatan manual untuk produksi keripik pisang. Pengabdian masyarakat ini bertujuan untuk mengoptimalkan kualitas dan kuantitas keripik pisang. Kegiatan pengabdian masyarakat yang telah dilakukan dengan memberikan pendampingan pengoperasian dan perawatan alat pemotong pisang dengan benar. Alat pemotong pisang sudah dimodifikasi menggunakan bahan food grade. Kualitas dan kuantitas dalam memproduksi keripik pisang menjadi lebih optimal. Alat pemotong pisang semi-otomatis diharapkan bisa membantu kelompok PKK desa Pacalan untuk meningkatkan produksi keripik pisang.
\end{abstract}

Kata kunci : pengabdian masyarakat, keripik pisang, desa, produksi

Abstract
Family welfare programme is activity empowers women to participate in supporting village development. Problem obtained from family welfare programme in Pacalan village because using manual equipment for production banana chips. Purpose for service community is optimizing the quality and quantity of banana chips. Community service activities that have been carried out by providing assistance in the proper operation and maintenance of banana cutting tools. The banana cutter has been modified using food grade materials. The quality and quantity in producing banana chips becomes more optimal. The semi-automatic banana cutter is expected to help the service community in Pacalan village to increase the production of banana chips.

Keywords : service community, banana chips, village, production

\section{PENDAHULUAN}

PKK adalah gerakan pembangunan nasional dalam pembangunan masyarakat yang tumbuh dari bawah yang pengelolaannya dari, oleh dan untuk masyarakat (Nurdewanto et al., 2015). Kegiatan PKK memberikan dampak yang positif demi kemajuan bersama untuk membangun sebuah desa yang produktif. Kemajuan desa dapat dilakukan dengan beberapa kegiatan yang perlu diagendakan supaya potensi desa terealisasi dengan baik. Potensi tersebut mendorong untuk meningkatkan ekonomi desa dalam membantu pendapatan desa demi kesejahteraan masyarakat. Perencanaan setiap kegiatan PKK perlu peran aktif masyarakat supaya berjalan lancar dan optimal. Pertumbuhan ekonomi masyarakat perlu dilakukan dengan upaya membangun kewirausahaan sesuai dengan potensi yang mendukung di desa.

Kegiatan usaha mikro, kecil dan menengah (UMKM) merupakan salah satu bidang usaha yang dapat berkembang dan konsisten dalam perekonomian nasional. Usaha mikro, kecil dan menengah (UMKM) menjadi wadah yang baik bagi penciptaan lapangan pekerjaan yang direncanakan baik oleh pemerintah, swasta dan pelakunya usaha perorangan (Halim, 2020). Kegiatan kewirausahaan desa perlu dilakukan dengan membangun UMKM yang terpusat untuk memberikan masyarakat pendampingan dan pelatihan dalam pengolahan potensi yang menonjol di desa. Pengolahan potensi yang mampu dijadikan UMKM biasanya olahan pangan dan kerajinan tangan. Masyarakat sebagai pelaku UMKM harus diberikan peralatan yang mendukung kualitas dan kuantitas pada produk yang akan dipasarkan. Tanpa adanya peralatan pendukung, maka masyarakat akan mengalami beberapa masalah dalam proses produksi. 
Berdasarkan survei yang dilakukan di desa Pacalan, kabupaten Magetan, Jawa Timur, perwakilan dari kelompok PKK mengeluhkan pembuatan keripik pisang masih menggunakan peralatan manual dengan konsekuensi produksi yang sedikit. Hal ini dapat dilihat, bahwa permasalahannya mengenai proses produksi yang perlu ditingkatkan. Perkembangan teknologi mesin industri yang semakin meningkat akan mendorong semua industri agar dapat mengadopsi teknologi tersebut untuk menghasilkan produk yang berkualitas (Jasasila, 2017). Peralatan yang memadai akan membantu masyarakat untuk meningkatkan produk keripik pisang secara kualitas dan kuantitas.

Tim Pengabdian kepada Masyarakat Universitas Tunas Pembangunan Surakarta, dapat membantu kelompok PKK desa Pacalan dengan memberikan peralatan semi - otomatis pemotong pisang yang nanti diharapkan dapat meningkatkan kuantitas produksi keripik pisang yang berkualitas.

\section{METODE}

Pengabdian kepada masyarakat (PkM) dilakukan di desa Pacalan, kecamatan Plaosan, kabupaten Magetan, Jawa Timur. Sasaran dalam kegiatan pengabdian masyarakat yaitu kelompok PKK desa Pacalan. Dalam PkM ini dilakukan 2 kegiatan, (1) Tata cara pengoperasian alat pemotong pisang, (2) Tata cara perawatan alat pemotong pisang. Pengoperasian alat pemotong pisang perlu dijelaskan dengan benar supaya pada proses produksi tidak mengalami kendala atau berhentinya proses produksi. Jumlah produksi dapat dimaksimalkan dengan mengoptimalkan produktivitas dari operator dalam menggunakan mesin produksi dan menempatkan setiap operator pada mesin yang tepat (Widyarto \& Triana, 2015). Selain dari pengoperasian juga harus dilihat juga dalam perawatan alat pemotong pisang. Produksi yang sering dilakukan, maka alat pemotong pisang perlu dilakukan perawatan secara berkala. Perawatan dapat mengurangi kemacetan atau kendala sekecil mungkin, sehingga sistem dapat bekerja secara efisien (Bangun et al., 2018).

\section{HASIL DAN PEMBAHASAN}

Kegiatan pengabdian kepada masyarakat yang dilakukan di desa Pacalan, kecamatan Plaosan, kabupaten Magetan, Jawa Timur. Kegiatan pengabdian masyarakat dihadiri oleh Kepala desa, staff balai desa, kelompok PKK, dan warga desa Pacalan. Kegiatan berlangsung di balai desa Pacalan yang bekerjasama dengan pihak desa dengan tetap patuh pada prokes untuk terhindar dari covid 19.

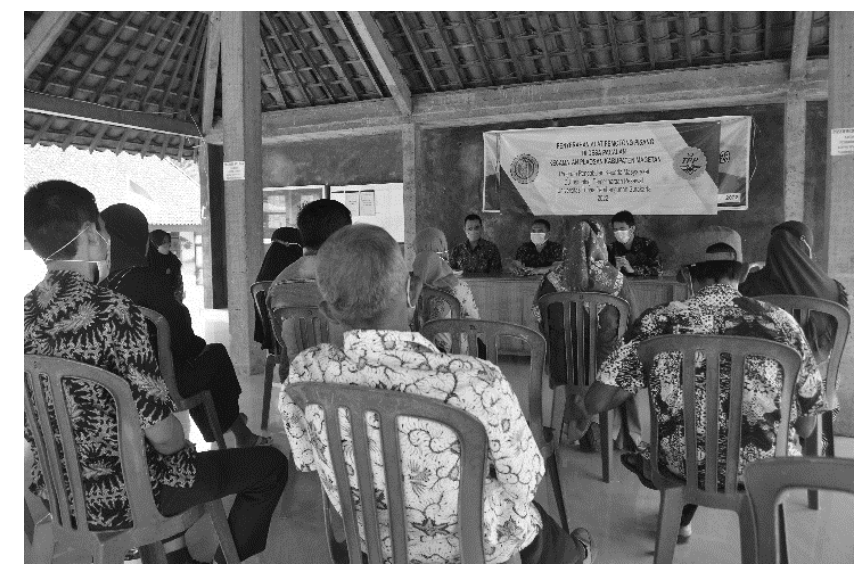

Gambar 1. Kegiatan PkM di balai desa Pacalan

Penyampaian kegiatan yang akan dilakukan oleh tim tentang pengoperasian dan perawatan alat pemotong pisang sebelum dilakukannya demo. Tata cara pengoperasian dan 
perawatan alat pemotong pisang yang baik dan benar juga akan memperlancar dari proses produksi. Perbandingan dengan penggunaan peralatan manual dengan tingkat produksi yang sangat rendah daripada menggunakan mesin. Kualitas dan kuantitas sebuah produksi dapat dilihat dari peralatan yang memadai dan kerja dari sumber daya manusia yang mumpuni.

Tim UTP melakukan demo dalam pengoperasian alat pemotong pisang dengan memberikan penjelasan prosedur pemakaian yang baik dan benar. Alat pemotong pisang terdapat 2 jenis bentuk potongan, yaitu lurus dan bulat. Bagian depan atas digunakan untuk membuat potongan lurus, sedangkan bagian belakang atas untuk membuat potongan bulat. Tempat memasukan pisang diharapkan selalu tertutup untuk menghindari kontaminasi dari luar. Mesin pemotong digerakan oleh motor yang dihubungkan oleh fanbelt ke bagian roda untuk memutar pisau yang terletak dibagian atas. Pisau yang dipakai sudah berbahan food grade yang dgunakan untuk menghindari partikel logam yang menempel di hasil potongan pisang.

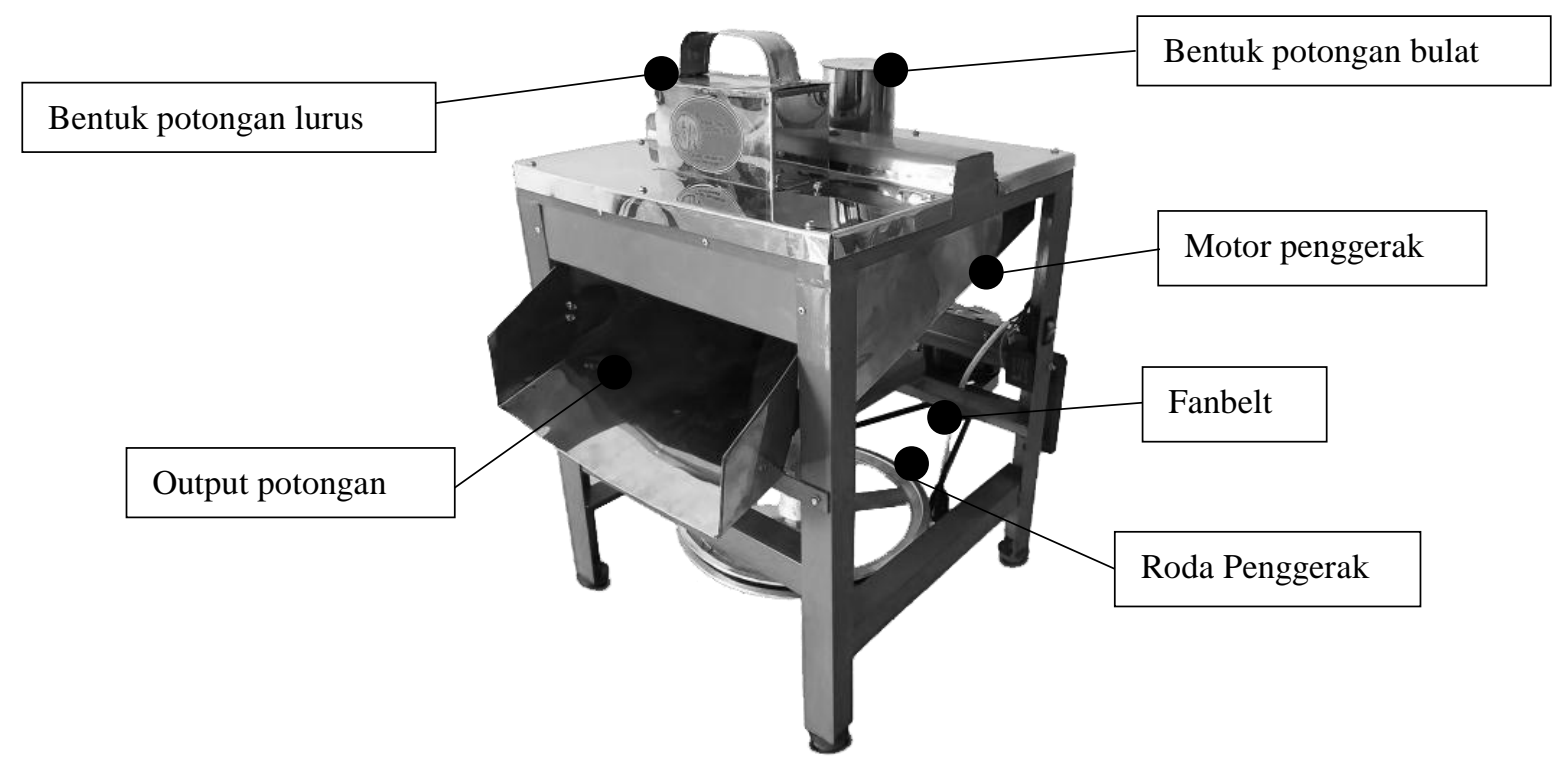

Gambar 2. Alat pemotong pisang

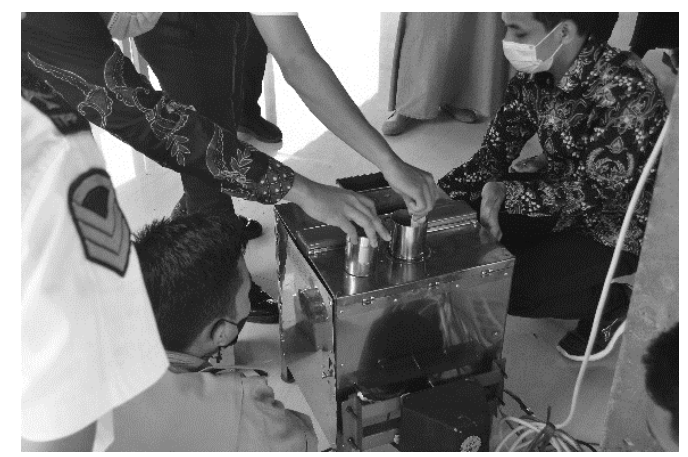

Gambar 3. Pengoperasian Alat Pemotong Pisang

Masyarakat melihat demo dalam tata cara pengoperasian alat pemotong pisang yang digunakan untuk memotong pisang dengan bentuk lurus maupun bulat. Dengan ini masyarakat terbantu untuk dapat memproduksi keripik pisang dengan kuantitas yang lebih banyak dibandingkan dengan yang manual. Hasil dari potongan mesin lebih rapi dan 
ketebalan bisa disesuaikan dengan yang diinginkan. Keselamatan saat proses produksi dalam pengoperasian mesin juga perlu diperhatikan. Pada saat pengoperasian, tangan harus pada kondisi kering supaya terhindar dari tersengat listrik. Saat proses produksi apabila terjadi kendala tersangkut/berhenti ditengah jalan maka mesin pada kondisi mati dahulu sebelum melakukan perbaikan.

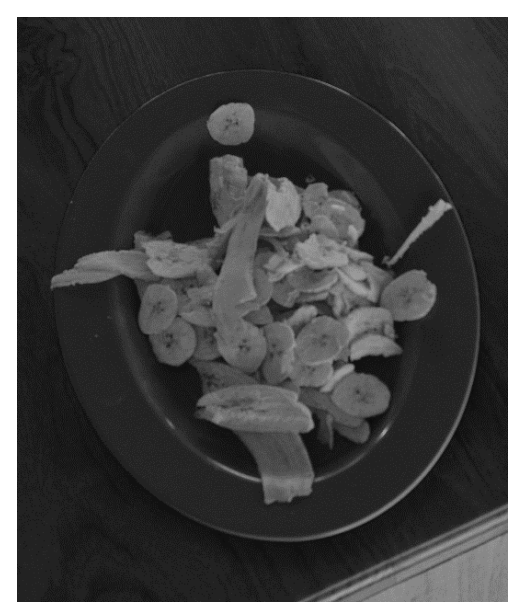

Gambar 4. Hasil Potongan Pisang

Perawatan yang dilakukan supaya alat pemotong pisang berumur panjang dan sering terjadi kendala pada saat proses produksi. Kendala - kendala yang sering terjadi akan mengakibatkan terganggunya proses produksi. Perawatan mesin yang perlu dilakukan, sebagai berikut :

a. Kebersihan area alat pemotong pisang supaya terhindar benda - benda yang mengakibatkan terjadi konsleting pada motor atau pun mengkontaminasi bahan baku pisang.

b. Mengasah pisau yang terdapat pada mesin pemotong supaya pada saat memotong menghasilkan bentuk potongan yang bagus dan rapi. Pada saat pelepasan pisau untuk diasah/diganti dengan membuka bagian penutup dan perlu diperhatikan untuk mematikan dulu alat pemotong pisang supaya terhindar dari kecelakaan.

Pada saat perawatan jangan terjadi kelalaian, dikarenakan dapat merusak alat pemotong pisang. Perawatan harus perlu diagendakan secara berkala agar tidak menggangu apabila sedang melakukan proses produksi. Kelebihan alat pemotong pisang sangat mudah untuk dilakukan perawatan sendiri. Pada perawatan sendiri juga perlu alat pendukung untuk mengamankan diri, seperti sarung tangan.

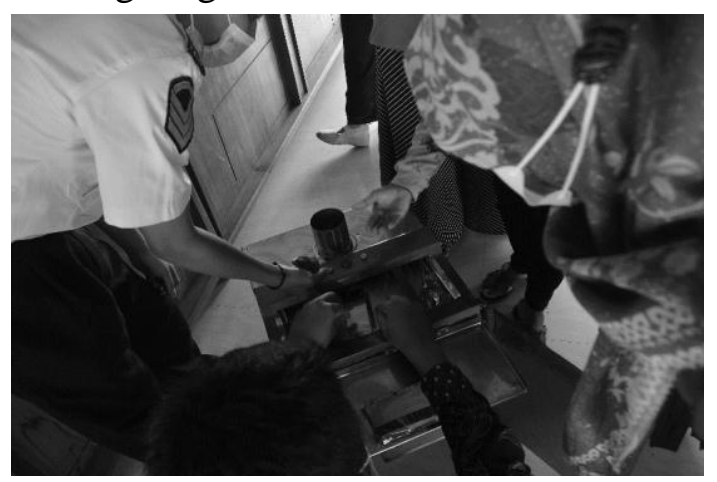

Gambar 5. Penjelasan Perawatan Alat pemotong pisang 
Masyarakat desa sangat antusias untuk mengetahui seluk beluk dari alat pemotong pisang tersebut. Pada saat demo pengoperasian dan perawatan selalu dilakukan tanya jawab kepada masyarakat desa yang telah hadir dalam kegiatan pengabdian kepada masyarakat. Adanya demo tersebut supaya alat pemotong pisang dapat bekerja secara optimal pada saat proses produksi keripik pisang.

\section{KESIMPULAN}

Alat pemotong pisang sangat membantu masyarakat, terutama kelompok PKK desa Pacalan untuk memproduksi keripik pisang dengan kuantitas dan kualitas yang bagus dengan skala produksi yang tidak sedikit. Pengoperasian dan perawatan mesin diharapkan mampu dilakukan dengan baik supaya alat pemotong pisang mampu bertahan lama untuk memproduksi keripik pisang. Dengan adanya mesin produksi dapat menjadi awal dari pertumbuhan ekonomi desa yang semakin maju dan meningkat. Produksi dengan skala besar masih belum bisa dijangkau karena hanya tersedia 1 mesin dengan sistem semi - otomatis.

\section{UCAPAN TERIMA KASIH}

Kegiatan pengabdian kepada masyarakat dapat terlaksana karena adanya bantuan dari berbagai pihak, oleh karena itu kami mengucapkan banyak terimakasih kepada :
a. Kepala desa Pacalan
b. Staff balai desa Pacalan
c. Kelompok PKK desa Pacalan
d. Tim pengabdian masyarakat UTP Surakarta
e. Mahasiswa prodi teknologi pemeliharaan pesawat

\section{DAFTAR PUSTAKA}

Bangun, I. Harnadi., Rahman, Arif., \& Darmawan, Zefry. (2018). Perencanaan Pemeliharaan Mesin Produksi Dengan Menggunakan Metode Reliability Centered Maintenance (RCM) II Pada Mesin Blowing OM (Studi Kasus: PT Industri Sandang Nusantara Unit Patal Lawang). Jurnal Rekayasa Dan Manajemen Sistem Industri (JRMSI), 2(5), 997-1008.

Halim, A. (2020). Pengaruh Pertumbuhan Usaha Mikro, Kecil Dan Menengah Terhadap Pertumbuhan Ekonomi Kabupaten Mamuju. Jurnal Ilmiah Ekonomi Pembangunan, 1(2), 157-172. https://stiemmamuju.ejournal.id/GJIEP/article/view/39

Jasasila. (2017). Peningkatan Mutu Pemeliharaan Mesin Pengaruhnya Terhadap Proses Produksi Pada Pt. Aneka Bumi Pratama (Abp) Di Kabupaten Batanghari. Jurnal Ilmiah Universitas Batanghari Jambi, 17(3), 96102.

Nurdewanto, B., Yuniriyanti, E., \& Sudarwati, R. (2015). Pemberdayaan Perempuan Melalui Kelompok Dasa Wiswa PKK. Jurnal Studi Manajemen Dan Bisnis, 2(1), 99-102. https://journal.trunojoyo.ac.id/jsmb/article/view/1506

Widyarto, W. O., \& Triana, D. (2015). Penugasan Operator Mesin Produksi dengan Menggunakan Metode Hungarian dan Algoritma Generate and Test. Jurnal Intech Teknik Industri, 1(1), 1-9. 